\title{
Assessing the Clinical Ethical Competence of Postgraduate Medical Students
}

\author{
C.B. Mhaske
}

Bioethics Unit Head and Dean, Dr. Shankarrao Chavan Government Medical College, Nanded. Corresponding Author: CB Mhaske

E-mail: drmhaskecb@yahoo.co.in

\begin{abstract}
Background: There has been rising public consciousness regarding the ethical conduct of medical practitioners, and complaints against physicians appear to be escalating. After completing their studies, healthcare professionals are expected to know ethical principles and apply them in their clinical practice. Hence, this study was conducted to assess clinical ethical competence of postgraduate medical students. The aim of the study was the assessment of the clinical ethical competence among postgraduate medical students of a medical college.

Methodology: Cross sectional study was conducted among post graduate Medical students in a Government medical college. After obtaining permission from Institutional ethics committee, the purpose of the study and nature of information which has to be furnished from the students was explained to them. Data was collected among 135 medical postgraduate students using pre tested self-administered questionnaire.

Results: 103 (76\%) have the ability to identify the moral aspects of medical practice. Very less awareness was found in ethical aspects of genetics i.e. $55(41 \%)$ and ethical aspects of transplantation/organ donation (43\%). $20 \%$ study subjects were not having any information about ethics.

Conclusion: The fact that many respondents had neutral opinion to some questions may indicate their lack of awareness or knowledge in that area and their inability to decide. Hence there should be sufficient training classes, workshops, conferences to stress the importance of ethical practice.
\end{abstract}

Keywords: Ethics, postgraduate medical students, competence.

\section{INTRODUCTION}

Health care decisions are based not only on clinical and technical grounds, but also on ethical grounds. Although we carefully weigh the clinical and technical aspects, ethical issues involved may be overlooked [1]. Training in medical ethics has been made mandatory in the medical curriculum by the regulatory body of medical education, the Medical Council of India (MCI). Medical Council of India in 2002 released its code of ethics which was a regulatory document on professional conduct, etiquette, and ethics of doctors [2].

There has been growing public awareness regarding the ethical conduct of medical practitioners, and complaints against physicians appear to be escalating [3]. This increase in litigation against doctors is issue of immediate concern. How doctors are trained, is regarded as a key element in determining the ethical and legal conduct within the healthcare sector However, on qualifying, healthcare professionals are expected to know about ethical practice during application of their skills [4]. 
Competency-based medical education (CBME) is gaining momentum across the globe. The Medical Council of India has described the basic competencies required of an Indian Medical Graduate and designed a competency-based module on attitudes and communication. Widespread adoption of a competency-based approach would mean a paradigm shift in the current approach to medical education [5]. Thus, focusing on above information we planned this present study to assess the clinical ethical competence of postgraduate medical students.

\section{METHODOLOGY}

This cross-sectional study was carried among postgraduate medical students in Dr. Shankarrao Chavan Government Medical College, Nanded, Maharashtra state, during March 2019. After obtaining permission from Institutional ethics committee, the purpose of the study and nature of information which has to be furnished from the students was explained to them. Those who are on leave, refused to participate were excluded from the study.

Data was collected among 135 students using a self-administered questionnaire. It was ensured that respondents understood the meaning of questions as well. Questionnaire included demographic details and questions on everyday ethical issues. They were asked if they agreed or disagreed with certain statements concerning ethical conduct, autonomy, paternalism, confidentiality, informing patients about wrongdoing and informing relatives about the patient's condition, informed consent.

To assess the ethical competencies, we used an array of assessment methods. Authentic and contextual Clinical scenarios with ethical issues (based on real life clinical situations) were used to assess postgraduate students' capacity to apply ethical principles in practice. This method of assessment was adapted from Module for Teaching Medical Ethics to medicos by World Health Organisation guidelines [6].

Collected data was entered in Excel and analysis was done using SPSS trial version 20. Analysed data were expressed in tables, graphs, percentages \& proportions.

\section{RESULTS}

Table 1 - Assessment of the clinical ethical competence among study participants

\begin{tabular}{|l|l|l|l|}
\hline No & Competency & Yes (\%) & No (\%) \\
\hline 1. & $\begin{array}{l}\text { The ability to identify the moral aspects of medical } \\
\text { practice. }\end{array}$ & $103(76)$ & $32(24)$ \\
\hline 2 & $\begin{array}{l}\text { The ability to obtain a valid consent or refusal of } \\
\text { treatment. }\end{array}$ & $85(63)$ & $50(37)$ \\
\hline 3 & $\begin{array}{l}\text { The knowledge of how to proceed if a patient is only } \\
\text { partially competent or fully incompetent. }\end{array}$ & $63(47)$ & $72(53)$ \\
\hline 4 & $\begin{array}{l}\text { The knowledge of how to proceed if a patient refuses } \\
\text { treatment. }\end{array}$ & $57(42)$ & $78(58)$ \\
\hline 5 & $\begin{array}{l}\text { The ability to decide when it is morally justifiable to } \\
\text { withhold information from a patient. }\end{array}$ & $82(61)$ & $53(39)$ \\
\hline 6 & $\begin{array}{l}\text { The ability to decide when it is morally justified to breach } \\
\text { confidentiality. }\end{array}$ & $70(52)$ & $65(48)$ \\
\hline 7 & $\begin{array}{l}\text { The knowledge of the moral aspects of caring for a patient } \\
\text { whose prognosis is poor. }\end{array}$ & $92(68)$ & $43(32)$ \\
\hline
\end{tabular}

After assessment of the clinical ethical competence among study participants it was found that out of 135 , majority i.e. $103(76 \%)$ have the ability to identify the moral aspects of medical practice, followed by $92(68 \%)$ had the knowledge of the moral aspects of caring for a patient whose prognosis is poor.

Only 57 (42\%) have the knowledge of how to proceed if a patient refuses treatment and $63(47 \%)$ have the knowledge of how to proceed if a patient is only partially competent or fully incompetent. 
Table 2: Assessment of Specific Ethical issues in study participants

\begin{tabular}{|l|l|l|l|}
\hline No. & Specific Ethical issues & Yes (\%) & No (\%) \\
\hline 1. & Ethical aspects of genetics & $55(41)$ & $80(59)$ \\
\hline 2. & Ethics of transplantation/organ donation & $58(43)$ & $77(57)$ \\
\hline 3. & Ethical aspects of treating the mentally ill & $81(60)$ & $54(40)$ \\
\hline 4. & Ethical issues in treating children & $103(76)$ & $32(24)$ \\
\hline 5. & Ethical aspects of treating patients with HIV/AIDS & $108(80)$ & $27(20)$ \\
\hline 6. & Ethics of public health and health promotion & $93(69)$ & $42(31)$ \\
\hline 7. & Principles of research ethics and research publication & $88(65)$ & $47(35)$ \\
\hline
\end{tabular}

Out of total, majority i.e. 108 (80\%) study participants were aware about ethical aspects of treating patients with HIV/AIDS, followed by 103 (76\%) aware about Ethical issues in treating children. Very less awareness was found in ethical aspects of genetics i.e. 55 (41\%) and ethical aspects of transplantation/organ donation (43\%).

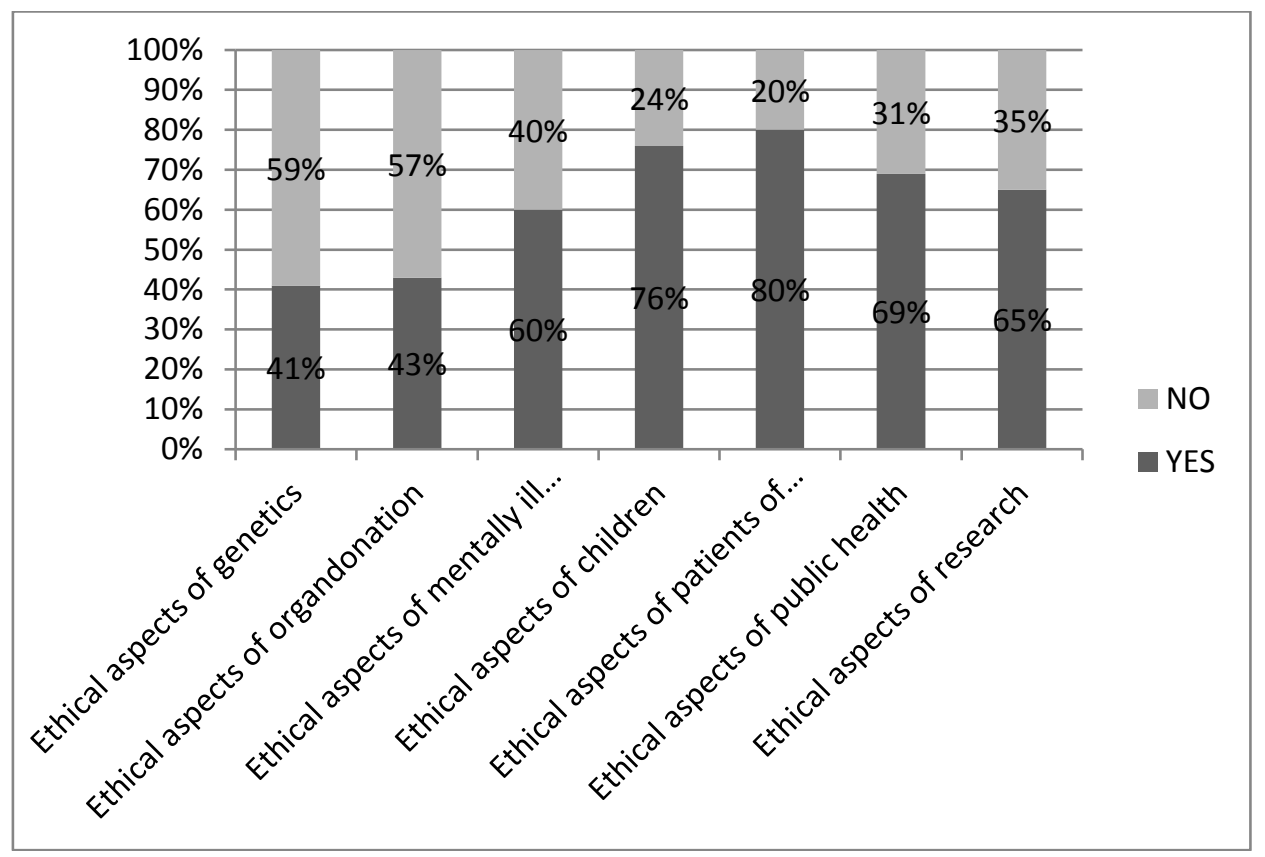

Bar diagram showing Assessment of Specific Ethical issues in study participants

Table 3: Distribution of study subject according to information received about ethics

\begin{tabular}{|l|l|}
\hline Source of information about ethics* & Frequency (\%) \\
\hline Books/ Journals & $112(83)$ \\
\hline During Clinical Postings & $80(59)$ \\
\hline In lectures & $69(51)$ \\
\hline Discussion with friends & $50(37)$ \\
\hline Told by Seniors & $85(63)$ \\
\hline Internet & $90(67)$ \\
\hline Media (Newspaper /TV) & $35(26)$ \\
\hline Don't have any information about such things & $27(20)$ \\
\hline
\end{tabular}

*Multiple Responses

Out of 135 study subjects, most of the study subjects (83\%) told book/ journals as a source of information about ethics, followed by internet (67\%). $20 \%$ study subjects were not having any information about ethics. 


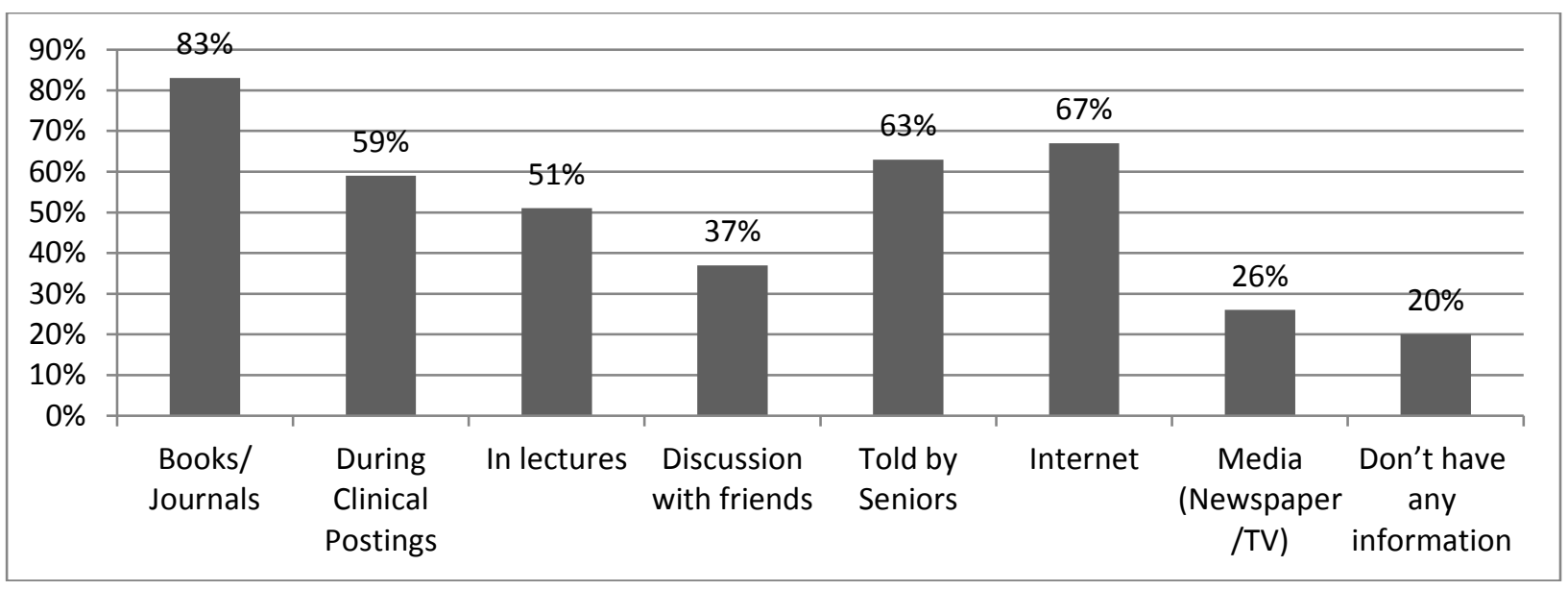

Distribution of study subject according to information received about ethics

Table 4 - Distribution of study subjects according to Knowledge on ethical codes

\begin{tabular}{|l|l|}
\hline Ethical codes & Frequency (\%) \\
\hline Knew the content of Hippocratic Oath & $88(65)$ \\
\hline Knew the content of Nuremberg Code & $45(33)$ \\
\hline Knew the content of Helsinki Code & $41(30)$ \\
\hline ICMR guidelines & $54(40)$ \\
\hline Not knowing about any of these & $27(20)$ \\
\hline \multicolumn{2}{|c|}{${ }^{*}$ Multiple Responses }
\end{tabular}

Out of 135 study subjects $20 \%$ study participants were unaware about knowledge of ethical codes, while only $30 \%$ were knew about content of Helsinki Code, $40 \%$ knows ICMR guidelines, $33 \%$ Knew the content of Nuremberg Code and $65 \%$ Knew the content of Hippocratic Oath.

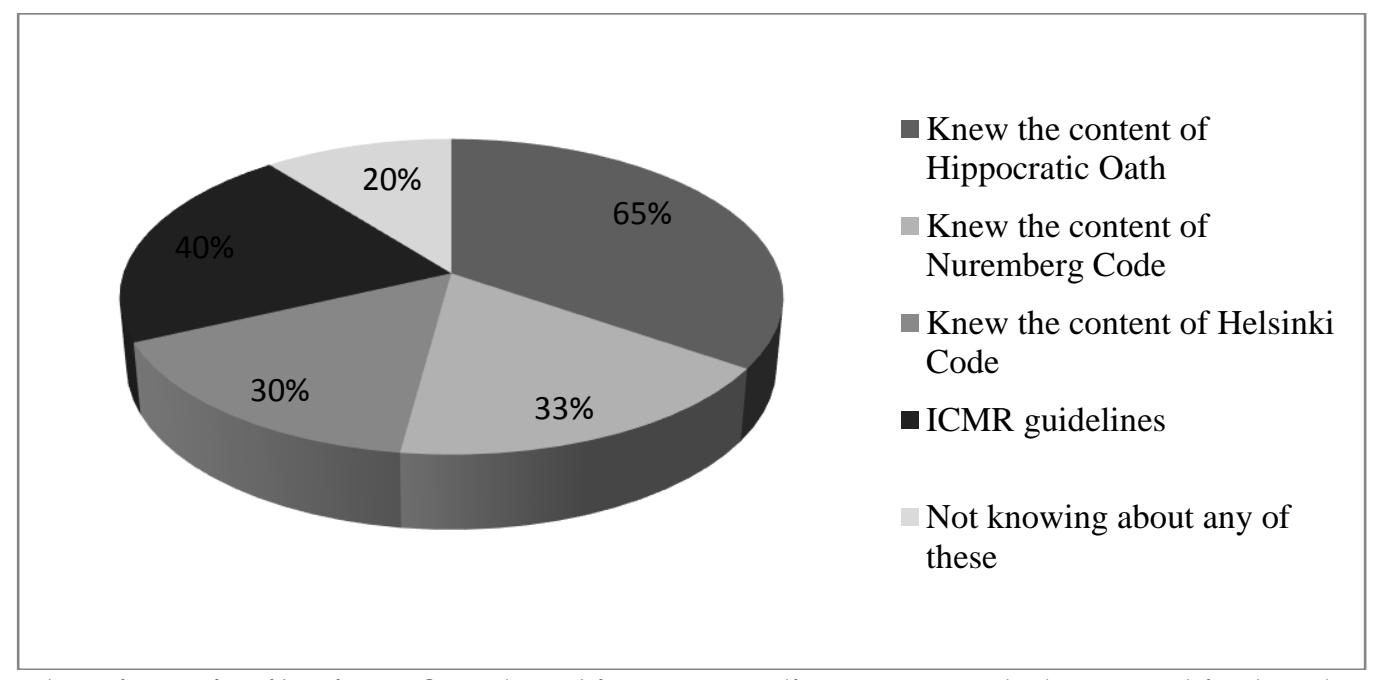

Showing Distribution of study subjects according to Knowledge on ethical codes

\section{DISCUSSION}

The aim of imparting medical education is to train medicos to efficiently take care of the health needs of the society. The current medical education system is based on a curriculum that is subjectcentred and time-based. Most evaluations are summative, with little opportunity for feedback. The 
teaching-learning activities and the assessment methods focus more on knowledge than on attitude and skills [7].

Thus, students may have extraordinary knowledge, but may lack the basic clinical skills required in practice. In addition, they may also lack the soft skills related to communication, doctor-patient relationship, ethics, and professionalism [8]. Considering these facts, the present was planned to assess the ethical competency among post graduate medical students. The findings of this study suggest that postgraduate medical students need more awareness regarding clinical ethics so as to handle the ethical and legal issues properly in their near future as they are the budding doctors of our society. The fact that many respondents had "no answer" to some questions may indicate their lack of awareness or knowledge in that area, their inability to decide or commit a specific response, or their disinterest.

Another major finding of the study was that the majority of the respondents did not know enough of the ethical codes pertaining to their workplace. Also, there were some students who did not know the contents of their respective codes. The fact that about more than half of the respondents had no knowledge regarding the Nuremberg Code and or the Helsinki Declaration indicates that there is very little knowledge regarding the ethics of research.

Bioethics or medical ethics has to be taught by a specialist in medical ethics. At present, the forensic and community medicine faculties teach medical ethics and they focus more on medical jurisprudence $[9,10]$. There is a need to encourage training of medical faculty in ethics or bioethics and eventually, to create a separate and independent department of medical ethics or bioethics.

\section{CONCLUSION}

Many of postgraduate medical students were either unaware of their importance or unable to appropriately deal with these clinical ethical issues. Since the findings of the study identify the lacunae's in the ethical competencies, there is a need to incorporate competencies regarding clinical ethics and sensitize them to these issues in the workplace. Practical education in ethics, particularly in a multidisciplinary setting and the incorporation of a bioethics curriculum in the initial period of the graduation and post-graduation programmes could assist in bridging the gap.

\section{REFERENCES}

1. Organisation mondiale de la santé, Conseil des organisations internationales des sciences médicales. Conférence (25:1990: Genève), Bankowski Z. Ethics and epidemiology: international guidelines: proceedings of the XXVth CIOMS Conference, Geneva Switzerland, 7-9 November 1990. CIOMS; 1991.

2. Gupta BD. The Indian medical council (professional conduct, etiquette and ethics) regulations, 2002: critical review and suggestions. J Forensic Med Toxicol 2003;20(1):4-7.

3. Chopra M, Bhardwaj A, Mithra P, Singh A, Siddiqui A, Rajesh DR. Current status of knowledge, attitudes and practices towards health care ethics among doctors and nurses from Northern IndiaA multicenter study. JKIMSU 2013;2(2):102-7.

4. Iswarya S, Bhuvaneshwari S. Knowledge and attitude related to medical ethics among medical students. Int J Commun Med Pub Health 2018;5(6):2222-5.

5. Shah N, Desai C, Jorwekar G, Badyal D, Singh T. Competency-based medical education: An overview and application in pharmacology. Indian J Pharmacol 2016;48(Suppl 1):S5-8.

6. World Health Organization. Module for teaching medical ethics to undergraduates. WHO Regional Office for South-East Asia; 2009.

7. Ten Cate O, Scheele F. Competency-based postgraduate training: can we bridge the gap between theory and clinical practice?. Acad Med 2007;82(6):542-7.

8. Chapman SJ, Glasbey JC, Khatri C, Kelly M, Nepogodiev D, Bhangu A, Fitzgerald JE. Promoting research and audit at medical school: evaluating the educational impact of participation in a student- 
led national collaborative study. BMC Med Educ 2015;15(1):47-52.

9. Code of Medical Ethics Regulations, 2002. Medical Council of India - Notification. [Internet]. New Delhi: MCI; 2002 Mar 11.

10. Janakiram C, Gardens SJ. Knowledge, attitudes and practices related to healthcare ethics among medical and dental postgraduate students in south India. Indian J Med Ethics 2014;11(2):99-104.

Acknowledgements: Nil

Funding: Nil

Conflict of Interest: Nil 